\title{
Mandatory fortification of bread with iodised salt modestly improves iodine status in schoolchildren
}

\author{
Sheila A. Skeaff* and Emily Lonsdale-Cooper \\ Department of Human Nutrition, University of Otago, PO Box 56, Dunedin 9054, New Zealand \\ (Submitted 8 February 2012 - Final revision received 6 June 2012 - Accepted 21 June 2012 - First published online 31 July 2012)
}

\section{Abstract}

Iodine deficiency has re-emerged in many parts of the world including the UK, Australia and New Zealand (NZ). In 2009, the NZ government introduced the mandatory fortification of bread with iodised salt as a strategy to improve iodine intakes. The aim of the present study was to assess the impact of fortification on the iodine status of NZ schoolchildren. A school-based cluster survey was used to randomly select schools from two NZ cities. Children aged 8-10 years were administered a general questionnaire, and asked to provide a casual urine and finger-prick blood sample. The median urinary iodine concentration (UIC) of the children $(n 147)$ was $113 \mu \mathrm{g} / \mathrm{l}$, which falls between 100 and $199 \mu \mathrm{g} / \mathrm{l}$ indicating adequate iodine status; $12 \%$ of children had a UIC $<50 \mu \mathrm{g} / \mathrm{l}$ and $39 \% \mathrm{had}$ a UIC $<100 \mu \mathrm{g} / \mathrm{l}$. The median serum thyroxine concentration was $115 \mathrm{nmol} / \mathrm{l}$. The median serum thyroglobulin ( $\mathrm{Tg}$ ) concentration was $10 \cdot 8 \mu \mathrm{g} / \mathrm{l}$ and falls in the $10 \cdot 0-19 \cdot 9 \mu \mathrm{g} / \mathrm{l}$ range indicative of mild iodine deficiency, suggesting that these children still had enlarged thyroid glands. When compared with the median UIC of $68 \mu \mathrm{g} / 1$ reported in the 2002 NZ Children's Nutrition Survey, the UIC of children in the present study had increased, which is probably caused by the addition of iodised salt to bread. However, the elevated concentration of Tg in these children suggests that the increase in UIC is not sufficient to ensure that thyroid volume has normalised. The fortification of other staple foods, in addition to bread, should be considered to ensure good iodine status in NZ children.

\section{Key words: Iodine: Deficiency: Fortification: Children}

Iodine deficiency was commonplace in many parts of the world for thousands of years. The introduction of iodised salt in the first half of the last century was viewed as a simple but practical solution to improve iodine intakes. In many countries where iodised salt was regularly used, iodine deficiency and, consequently, goitre all but disappeared, leading to a sense of complacency that the problem was solved. However, a change in food habits has led to a re-emergence of iodine deficiency in many parts of the world including the $\mathrm{UK}^{(1)}$, Australia ${ }^{(2)}$ and New Zealand $(\mathrm{NZ})^{(3)}$. A decrease in the use of iodised salt at the table and in cooking in response to public health messages to decrease $\mathrm{Na}$ intakes, the rising popularity of rock or sea salt with negligible amounts of iodine, Western diets that contain relatively small amounts of fish and other seafood, and an increase in the intake of processed foods prepared by a food industry reluctant to use iodised salt explain the decline in iodine intakes observed over the last 20 years. The WHO recommends universal salt iodisation (USI) whereby all salt for human and animal consumption is iodised ${ }^{(4)}$. Not surprisingly, the most successful implementation of USI has occurred in China, which has seen a reduction in the prevalence of iodine deficiency from approximately 34 to $16 \%$ between 1995 and $2007^{(5)}$. However, USI can also be accompanied by an increase in iodine excess ${ }^{(6)}$. Rather than USI, a more graduated approach has been adopted in some countries, whereby a limited number of foods are fortified, which has the potential to alleviate iodine deficiency without iodine excess. This strategy also appeals to the food industry, as importing restrictions in some countries can make widespread fortification of foods difficult. In response to the re-emergence of iodine deficiency in NZ, the government introduced the mandatory fortification of bread with iodised salt in 2009. The aim of the present study was to assess the impact of mandatory fortification of bread on the iodine status of schoolchildren.

\section{Methods}

A school-based cluster survey was used to randomly select schools from two NZ cities, Dunedin in the South Island and Wellington in the North Island between November 2010 and February 2011. In schools that consented to take part, all children aged 8-10 years were given an information

Abbreviations: NZ, New Zealand; NZEO, New Zealand European and other ethnicity; T4, thyroxine; Tg, thyroglobulin; UIC, urinary iodine concentration; USI, universal salt iodisation.

* Corresponding author: S. A. Skeaff, fax +64 34797958 , email sheila.skeaff@otago.ac.nz 
pack about the study to take home and parents were asked to indicate interest in participating by return post or email. Children and their caregivers were then contacted by telephone and assigned interview times. The interview was carried out on the school premises by two trained research personnel. The present study was conducted according to the guidelines laid down in the Declaration of Helsinki and all procedures involving human subjects were approved by the University of Otago Ethics Committee (10/167). Written informed consent was obtained from all children and their parents.

A general questionnaire was administered to each child to obtain information on the child's birthday, ethnicity (i.e. NZ European and other ethnicity (NZEO), Māori or Pacific), general health, use of medications or dietary supplements, which also contained a FFQ. Children were asked about their frequency of consumption of foods over the previous 3 months that are good sources of iodine. Foods included were as follows: milk; dairy products; red meat; chicken; fish; seafood; eggs; iodised salt; fortified bread. The frequency-of-use response categories were as follows: daily; weekly; monthly; rarely; or unknown. Information on typical serving sizes was not obtained. Using data obtained from the FFQ, the average total iodine intake (i.e. iodine content and standard serving sizes) was calculated using the NZ Food Composition Database (FOODFiles 2006) ${ }^{(7)}$. The iodine content of fortified bread was determined by using the $\mathrm{Na}$ content of bread, and assuming that $90 \%$ of $\mathrm{Na}$ in bread comes from iodised salt with an iodine concentration of $45 \mathrm{mg} / \mathrm{kg}$ salt. Parents not present during the interview were phoned to confirm the responses of the children to the questionnaire.

Anthropometric measurements were obtained according to standardised techniques ${ }^{(8)}$ using calibrated equipment with children wearing light indoor clothing and no shoes. Height was measured to the nearest $0 \cdot 1 \mathrm{~cm}$ with a portable stadiometer designed and built by the University of Otago. Weight was measured to the nearest $100 \mathrm{~g}$ using Seca digital platform scales (Model 770, Alpha; CMS Weighing Equipment Limited).

A non-fasting $1 \mathrm{ml}$ finger-prick blood sample was collected from each child for the determination of serum thyroglobulin (Tg) and total thyroxine (T4) concentrations. To facilitate blood flow, a wheat bag was heated in a microwave and wrapped around the child's hand for $5 \mathrm{~min}$ before blood was collected in a $1.5 \mathrm{ml}$ Eppendorf tube using a disposable lancet (Tenderlett; International Technidyne Corporation). Whole blood was left to clot for $60 \mathrm{~min}$, spun in a microcentrifuge for $10 \mathrm{~min}$, serum isolated and frozen at $-20^{\circ} \mathrm{C}$. Tg and total T4 concentration were determined using an electrochemiluminescent immunoassay (Roche) on an Elecsys 2010 analyser by a single technician. The analytical range for $\mathrm{Tg}$ was $0 \cdot 1-1000 \mu \mathrm{g} / \mathrm{l}$. Analysis of pooled serum samples obtained from adults, used for quality control $(n 10)$, had a mean of $13.2(\mathrm{SD} 0.7) \mu \mathrm{g} / \mathrm{l}$ and a CV of $5.7 \%(n$ 13). The mean for $\mathrm{Tg}$ of the internal controls supplied by the manufacturer was $27 \cdot 3(\mathrm{SD} 1 \cdot 8) \mu \mathrm{g} / \mathrm{l}$ (expected range $20 \cdot 2-33 \cdot 0 \mu \mathrm{g} / \mathrm{l}$ ) and $82 \cdot 1$ (SD 3.5) $\mu \mathrm{g} / \mathrm{l}$ (expected range 61.9-101.1 $\mu \mathrm{g} / \mathrm{l}$ ). In order to facilitate comparisons with previous published literature in
NZ that had used the RIA method, the pooled adult serum samples ( $n$ 9) were also analysed by RIA (EndoLab, Christchurch Hospital), resulting in a mean $\mathrm{Tg}$ concentration of $7 \cdot 7$ (SD $0 \cdot 1) \mu \mathrm{g} / \mathrm{l}$. A correction factor of 0.588 was used to adjust for intra-assay variation in $\mathrm{Tg}$ concentration between the two methods. The analytical range for T4 was 5.4$320.0 \mathrm{nmol} / \mathrm{l}$ with a CV of $2 \cdot 2 \%(n$ 12). The mean for T4 of the two internal controls was 105.8 (SD $4 \cdot 1$ ) nmol/1 (expected range $83 \cdot 7-128.3 \mathrm{nmol} / \mathrm{l}$ ) and $159 \cdot 9(\mathrm{SD} \mathrm{3.4}) \mathrm{nmol} / \mathrm{l}$ (expected range $125 \cdot 6-192 \cdot 4 \mathrm{nmol} / \mathrm{l})$.

Children were asked to void urine into a clean plastic bowl that was fitted into a toilet. Urine was then transferred to a $5 \mathrm{ml}$ plastic test-tube and frozen at $-20^{\circ} \mathrm{C}$. Urinary iodine concentration (UIC) was determined using a modification of the method of Pino et al. $^{(9)}$ and performed by a single technician. Internal and external standards were run with each batch of samples. The internal standard used was a pooled urine sample (mean $65.9(\mathrm{SD} 0.5) \mu \mathrm{g} / \mathrm{l}$ ), which gave a CV of $7 \cdot 4 \%$ ( $n$ 23). Seronorm (Sero As) was used as an external standard, which had a mean iodine concentration of $144 \cdot 8$ (SD 0.4$) \mu \mathrm{g} / 1$ (expected range $131-150 \mu \mathrm{g} / \mathrm{l}$ ) and a CV of $2 \cdot 3 \%$ ( $n$ 23).

All statistical analyses were carried out using the statistical package STATA 11.1 (StataCorp LP) using the SVY command. Sampling weights were calculated based on the probability of a child being selected to participate in each city. Log transformation was carried out for data that were not normally distributed (i.e. UIC). Linear regression was used to determine the effect of age, sex (boy or girl) and ethnicity (NZEO, Māori and Pacific) on UIC, Tg, T4 and total iodine intake, and the effect of a UIC $<50$ and $<100 \mu \mathrm{g} / 1$ on Tg and T4. Regression analysis was also undertaken to ascertain whether the percentage contribution to the total iodine intake from the different food groups was associated with UIC. All tests were two-sided and the level of significance set at $P<0 \cdot 05$.

\section{Results}

In Dunedin, there were forty-one eligible schools with a total school roll of 6217 children; nine of the eleven schools randomly selected to participate agreed to take part, with sixtyeight Dunedin children studied. In Wellington, there were fifty-six eligible schools with a total school roll of 14259 children; nine of the thirty-two schools randomly selected agreed to take part, with seventy-nine Wellington children studied. The sociodemographic characteristics of children ( $n$ 147) in the present study were similar to national data collected in NZ's only Children's Nutrition Survey ${ }^{(3)}$ undertaken in 2002 and the 2006 NZ Census ${ }^{(10)}$ (Table 1), although there were more children (i.e. $89 v$. 79\%) in the present study who were NZEO and more children had a healthy BMI ${ }^{(11)}$ (i.e. 76 v. 69\%). Schools in NZ are given a decile rating based on the proportion of children attending that school who are from a lower socio-economic status ${ }^{(12)}$. In the present study, $52 \%(v$. the expected $30 \%$ ) of the schools were ranked in the top three deciles, which indicates that proportionally more children in the present study were of high socio-economic status. A sample of urine was collected from 147 children 
Table 1. Comparison of sociodemographic characteristics of the study children with New Zealand (NZ) children

\begin{tabular}{lrcc}
\hline Variables & $n$ & Study children (\%) & NZ children (\%) \\
\hline Sex & & & \\
$\quad$ Boys & 74 & 50 & 49 \\
$\quad$ Girls & 73 & 50 & 51 \\
Age (years) & & & \\
8 & 54 & 37 & NA \\
9 & 52 & 35 & \\
10 & 41 & 28 & 79 \\
Ethnicity & & & 21 \\
NZEO & 131 & 89 & \\
Māori/Pacific & 16 & 11 & 31 \\
BMl (kg/m ${ }^{2}$ ) & & & \\
$\quad$ Normal weight $\dagger$ & 111 & 76 & \\
$\quad$ Overweight/obese & 35 & 24 & \\
\hline
\end{tabular}

NA, not applicable; NZEO, NZ European and other ethnicity.

${ }^{\star} \mathrm{NZ}$ Census Data ${ }^{(10)}$, unless stated otherwise.

$\dagger$ As determined by Cole et al. ${ }^{(11)}$.

$\ddagger$ Parnell et al. ${ }^{(3)}$

and enough blood for the determination of $\mathrm{T} 4$ and $\mathrm{Tg}$ from 112 children. Complete FFQ were obtained from 144 children.

The median UIC of children was $113 \mu \mathrm{g} / \mathrm{l}$, which falls between 100 and $199 \mu \mathrm{g} / \mathrm{l}$ indicating that the children had adequate iodine status ${ }^{(4)}$ (Table 2). Furthermore, $12 \%$ of the children had a UIC $<50 \mu \mathrm{g} / 1$ and $39 \%$ had a UIC $<100 \mu \mathrm{g} / 1$, below the 20 and $50 \% \mathrm{WHO} / \mathrm{UNICEF} / \mathrm{ICCIDD}$ (International Council for the Control of Iodine Deficiency Disorders) recommendations. Using regression analysis, there was no significant effect of age $(P=0.398)$, sex $(P=0.947)$, ethnicity $(P=0 \cdot 167)$ or total iodine intake $(P=0.687)$ on UIC. The median T4 concentration of children was $115 \mathrm{nmol} / \mathrm{l}$, which falls in the normal reference range suggested by Zurakowski et $a l .{ }^{(13)}$. There were three children who had a T4 concentration below the lower limit of the reference range (i.e. $<75 \mathrm{nmol} / \mathrm{l})$. Boys had a significantly lower T4 concentration than girls (111 v. $120 \mathrm{nmol} / \mathrm{l} ; P=0 \cdot 019)$. The median Tg concentration of $10 \cdot 8 \mu \mathrm{g} / \mathrm{l}$ lies between 10.0 and $19 \cdot 9 \mu \mathrm{g} / \mathrm{l}$ and indicates that these children were mildly iodine deficient ${ }^{(4)}$. NZEO children had a significantly lower $\mathrm{Tg}$ concentration than Māori and Pacific children (11.8 v. 15.9 $\mu \mathrm{g} / \mathrm{l} ; P=0.034)$. There was no effect of having a UIC $<50$ or $<100 \mu \mathrm{g} / \mathrm{l}$ on either $\mathrm{T} 4$ or $\mathrm{Tg}$ concentration.
The mean iodine intake was 125 (SD 41) $\mu \mathrm{g} / \mathrm{d}$. Using regression analysis, there was no significant effect of age $(P=0.441)$, sex $(P=0.790)$ or ethnicity $(P=0.230)$ on total iodine intake. Table 3 presents the percentage contribution to the iodine intake from the main food groups from the FFQ data obtained from children in the present study, compared with published estimates using dietary modelling of $24 \mathrm{~h}$ recall data obtained from the NZ Children's Nutrition Survey ${ }^{(14)}$. Using these modelled estimates, before fortification, $40 \%$ of total iodine in NZ children came from milk and dairy products, whereas after fortification this decreased to $20 \%$, with $47 \%$ of total iodine contributed from bread. Data obtained from children in the present study using a FFQ found that bread contributed $28 \%$ of iodine intakes. The percentage of iodine from bread was significantly associated with UIC $(P=0.017)$ in children in the present study, but none of the other foods or food groups assessed in the FFQ was associated with UIC. The majority (56\%) of children in the present study reported never using iodised salt at the table and $29 \%$ of the children's parents never used iodised salt in cooking.

\section{Discussion}

The mandatory fortification of bread with iodised salt has improved the iodine status of NZ schoolchildren as assessed by UIC; the UIC of children in the present study was $113 \mu \mathrm{g} / \mathrm{l}$, higher than the $68 \mu \mathrm{g} / \mathrm{l}$ observed in the NZ Children's Nutrition Survey conducted in $2002^{(15)}$. A concomitant decline in Tg concentration was also observed in the present sample of children; however, the median Tg concentration of $10 \cdot 8 \mu \mathrm{g} / 1$ does fall within the $10 \cdot 0-19 \cdot 9 \mu \mathrm{g} / \mathrm{l}$ range specified by the WHO/UNICEF/ICCIDD which is indicative of mild iodine deficiency ${ }^{(4)}$. In healthy children, an elevated level of Tg suggests enlargement of the thyroid gland or goitre. A similar study undertaken in 1998 of children living in Dunedin and Wellington found a median UIC of $66 \mu \mathrm{g} / \mathrm{l}^{(16)}$, and although $\mathrm{Tg}$ concentration was not measured in this earlier study, a reanalysis of the data using revised cut-offs for thyroid volume found that $30 \%$ of children had goitre (SA Skeaff, unpublished results). Thus, before fortification, it is likely that large numbers

Table 2. Iodine status of New Zealand children before and after fortification of bread with iodised salt (Median values and 25th and 75th percentiles)

\begin{tabular}{|c|c|c|c|c|c|}
\hline \multirow[b]{2}{*}{ Index of iodine status } & \multicolumn{2}{|c|}{$\begin{array}{l}\text { Pre-fortification (published } \\
\text { studies) }\end{array}$} & \multicolumn{2}{|c|}{ Post-fortification (this study) } & \multirow[b]{2}{*}{ Recommended' } \\
\hline & Median & 25th, 75th percentile & Median & 25th, 75th percentile & \\
\hline UIC $(\mu \mathrm{g} / \mathrm{l})$ & $68 \dagger$ & 50,95 & 113 & 78,159 & $100-300$ \\
\hline$\%$ UIC < $50 \mu \mathrm{g} / \mathrm{l}$ & & $28 \dagger$ & & 12 & $<20$ \\
\hline$\%$ UIC $<100 \mu \mathrm{g} / \mathrm{l}$ & & $82 \dagger$ & & 39 & $<50$ \\
\hline $\operatorname{Tg}(\mu \mathrm{g} / \mathrm{l})$ & $12.9 \dagger$ & $8 \cdot 1,19 \cdot 1$ & $10 \cdot 8$ & $7 \cdot 2,16 \cdot 8$ & $<10.0$ \\
\hline Total T4 (nmol/l) & $101 \ddagger$ & 93,113 & 115 & 104,124 & $75-154 \S$ \\
\hline
\end{tabular}

UIC, urinary iodine concentration; Tg, thyroglobulin; T4, thyroxine.

${ }^{*}$ WHO/UNICEF/ICCIDD (International Council for the Control of lodine Deficiency Disorders) ${ }^{(4)}$, unless stated otherwise.

† Skeaff et al. ${ }^{(15)}$

$\ddagger$ Gordon et al. ${ }^{(19)}$.

$\S$ Reference range adapted from Zurakowski et al. ${ }^{(13)}$ 
Table 3. Contribution of the main food groups to iodine intakes in New Zealand children

\begin{tabular}{|c|c|c|c|}
\hline \multirow[b]{2}{*}{ Food group } & \multicolumn{3}{|c|}{ Published estimates* } \\
\hline & Pre-fortification (\%) & Post-fortification (\%) & This study (\%) \\
\hline Milk and dairy products & 40 & 20 & 18 \\
\hline Eggs & 8 & 4 & 4 \\
\hline Fish and seafood & 6 & 3 & 4 \\
\hline Meat & 7 & 4 & 11 \\
\hline Bread & 1 & 47 & 28 \\
\hline
\end{tabular}

* Ministry of Agriculture and Forestry ${ }^{(14)}$.

of NZ children had goitre, which would be associated with an elevated $\mathrm{Tg}$ concentration.

A lag between an improvement in UIC and a decline in goitre rates has been observed in other countries after the introduction of strategies to improve iodine status. Erdogan et $a l .{ }^{(17)}$ found that it took 10 years after the introduction of iodised salt for the prevalence of goitre to decrease from 25 to $1 \%$ in Turkish children. UIC is a marker of short-term (i.e. days) iodine status, while thyroid volume is a marker of longer-term (i.e. years) iodine status. Tg, however, has been proposed to be a more sensitive marker of recent iodine status (i.e. months) ${ }^{(18)}$. There is a discrepancy between the UIC and Tg concentration of children in the present study, which may have two possible explanations. First, it may be that insufficient time has elapsed between improved iodine intakes (reflected in increased UIC) in these children and a reduction in thyroid volume. However, in a randomised trial conducted in 2007 of iodine-deficient NZ children living in Dunedin $^{(19)}$, daily supplementation with $150 \mu \mathrm{g}$ iodine for 7 months increased UIC from 62 to $145 \mu \mathrm{g} / \mathrm{l}$ and decreased $\mathrm{Tg}$ concentration from 16.5 to $8.5 \mu \mathrm{g} / \mathrm{l}$, suggesting that 7 months should be sufficient time to observe a change in $\mathrm{Tg}$ in a population moving from mild iodine deficiency to adequate iodine status. A second explanation is that the iodine status of NZ children has not improved sufficiently to alleviate thyroid hyperplasia and cause a meaningful decline in $\mathrm{Tg}$ concentration (i.e. below $<10.0 \mu \mathrm{g} / \mathrm{l}$ ). The median UIC of 113 observed in the present study is very close to the low end of the 100-199 $\mu \mathrm{g} / \mathrm{l}$ range of iodine sufficiency. If this second explanation is true, then the mandatory fortification of bread alone with iodised salt has not been an effective strategy to sufficiently improve iodine intakes in NZ children.

The accurate determination of iodine intakes using dietary assessment is problematic because the contribution of iodised salt used at the table and in cooking to the total iodine intake is difficult to quantify. To address this issue, two approaches have been employed in NZ. The first approach does not include iodine from discretionary salt, and was used in the 2009 NZ Total Diet Study ${ }^{(20)}$. The second approach assumes that NZ children consume $1 \mathrm{~g}$ of iodised salt per $\mathrm{d}$, which contributes $48 \mu \mathrm{g}$ iodine, and was used in a recent government report to estimate iodine intakes in NZ children, before and after fortification $^{(14)}$. The authors of this report used dietary modelling of $24 \mathrm{~h}$ recall data collected from 5 to 14 years old children who took part in the NZ Children's Nutrition Survey. Regardless of the approach, milk and dairy products were the main source of iodine in the diets of NZ children before fortification. When the iodine content of fortified bread was used in the report with dietary modelling, the contribution from bread increased from $1 \%$ before fortification to $47 \%$ after fortification, making bread the largest contributor to the total iodine intake. We found that bread provided less iodine (i.e. $28 \%$ ) to the total iodine intake, but was still the main provider of dietary iodine after fortification.

In conclusion, when mandatory fortification was first explored in NZ, other foods were considered including sweet biscuits and breakfast cereals; however, only bread was chosen as a vehicle due to concerns that some groups of the population would have excessive intakes of iodine. Although the UIC of NZ children has increased, which is most probably caused by the addition of iodised salt to bread, the elevated concentration of Tg suggests that they may not have adequate iodine status. The fortification of other staple foods, in addition to bread, should be considered to ensure good iodine status in NZ children. Research is also needed to assess the impact of fortification on the iodine status of other vulnerable groups in the population such as pregnant women.

\section{Acknowledgements}

Grateful appreciation is extended to the principals and teachers of the participating schools, and all the children and their parents who took part in this study. The study was funded by the Department of Human Nutrition at the University of Otago. We would like to thank Guillaume Tondeur for assisting with data collection and data entry in Dunedin, Holiday Wilson for conducting the urinary iodine analysis, and Michelle Harper for the blood analysis. S. A. S. conceived the study, obtained funding and ethical consent, was involved in the data collection, undertook the statistical analysis, and wrote the manuscript. E. L.-C. was involved in the data collection and data entry in Dunedin and Wellington, particularly of the dietary data, and assisted with data cleaning. The authors declare that they have no conflict of interest.

\section{References}

1. Vanderpump MPJ, Lazarus JH, Smyth PP, et al. (2011) Iodine status of UK schoolgirls: a cross-sectional survey. Lancet 377, 2007-2012. 
2. Li M, Eastman CJ, Waite KV, et al. (2006) Are Australian children iodine deficient? Results of the Australian National Iodine Nutrition Study. Med J Aus 184, 165-169.

3. Parnell W, Scragg R, Wilson N, et al. (2003) NZ Food NZ Children: Key Results of the 2002 National Children's Nutrition Survey. Wellington: Ministry of Health.

4. World Health Organization, United Nations International Children's Fund \& International Council for the Control of Iodine Deficiency Disorders (2007) Assessment of Iodine Deficiency Disorders and Monitoring their Elimination: A Guide for Programme Managers, 3rd ed. Geneva: WHO.

5. World Health Organization (2007) WHO Global Database on Iodine Deficiency. Geneva: WHO. http://who.int/vmnis/ iodine/data/database/countries/chn_idd.pdf

6. Sang Z, Wang PP, Yao Z, et al. (2012) Exploration of the safe upper level of iodine intake in euthyroid chinese adults: a randomized double-blind trial. Am J Clin Nutr 95, 367-373.

7. Crop and Food Research (2006) FOODFiles 2006. Palmerston North: New Zealand Institute for Crop and Food Research. http://www.foodcomposition.co.nz/

8. TG Lohman, AF Roche and R Martorell (editors) (1988) Anthropometric Standardization Reference Manual. Champaign, IL: Human Kinetics.

9. Pino S, Fang SL \& Braverman LE (1998) Ammonium persulfate: a new and safe method for measuring urinary iodine by ammonium persulfate oxidation. Exp Clin Endocr Diab 106, S22-S27.

10. Statistics NZ (2008) 2006 Census Data. Wellington: Statistics New Zealand.

11. Cole TJ, Bellizzi MC, Flegal, et al. (2000) Establishing a standard definition for child overweight and obesity worldwide: international survey. BMJ 320, 1240-1243.

12. Ministry of Education (2011) Funding, Staffing and Allowances Handbook. Chapter 1, Operational Funding.
Wellington: Ministry of Education. http://www.minedu. govt.nz/NZEducation/EducationPolicies/Schools/School Operations/Resourcing/ResourcingHandbook/Chapter1/ DecileRatings.aspx

13. Zurakowski D, Di Canzio J \& Majzoub JA (1999) Pediatric reference values for serum thyroxine, tri-iodothyronine, thyrotropin, and free thyroxine. Clin Chem 45, 1087-1091.

14. Ministry of Agriculture and Forestry (2012) Dietary iodine intake of New Zealand children following fortification of bread with iodine. MAF Technical Paper No. 2012/02. Wellington, NZ. http://www.foodsafety.govt.nz/elibrary/ind ustry/child-iodine-intake-bread.pdf

15. Skeaff SA, Thomson CD, Wilson N, et al. (2012) A comprehensive assessment of urinary iodine concentration and thyroid status in New Zealand schoolchildren: a cross sectional survey. Nutr J 11, 31 .

16. Skeaff SA, Thomson CD \& Gibson RS (2002) Mild iodine deficiency in a sample of NZ schoolchildren. Eur J Clin Nutr 56, 1169-1175.

17. Erdogan MF, Demir O, Kamel AN, et al. (2009) More than a decade of iodine prophylaxis is needed to eradicate goiter among school age children in a modestly iodine-deficient region. Thyroid 19, 265-268.

18. Vejbjerg P, Knudsen N, Perrild H, et al. (2009) Thyroglobulin as a marker of iodine nutrition status in the general population. Eur J Endocrinol 161, 475-481.

19. Gordon RC, Rose MC, Skeaff S, et al. (2009) Iodine supplementation improves cognition in mildly iodine deficient children. Am J Clin Nutr 90, 1264-1271.

20. Ministry of Agriculture and Forestry (2011) 2009 New Zealand Total Diet Study. Wellington: Ministry of Agriculture and Forestry. http://www.foodsafety.govt.nz/elibrary/ industry/total-diet-study.pdf 